\title{
Spatial patterns and response to wave exposure of shallow water algal assemblages across the Canarian Archipelago: a multi-scaled approach
}

\author{
Fernando Tuya ${ }^{1,2, *}$, Ricardo J. Haroun ${ }^{1}$ \\ ${ }^{1}$ BIOGES, Department of Biology, Campus Tafira, University of Las Palmas de Gran Canaria, \\ 35017 Las Palmas, Canary Islands, Spain \\ ${ }^{2}$ Present address: Center for Ecosystem Management, Edith Cowan University, 100 Joondalup Drive, \\ Joondalup, Western Australia 6027, Australia
}

\begin{abstract}
We conducted a mensurative survey to investigate spatial variability and the effect of wave exposure at a range of spatial scales including islands (100s of $\mathrm{km}$ apart), locations within islands (10s of $\mathrm{km}$ apart), and sites within locations (100s of $\mathrm{m}$ apart), on the composition, abundance and distribution of shallow water algal assemblages across subtidal hard bottoms of the Canarian Archipelago (eastern Atlantic). A multi-scaled hierarchical sampling design provided the framework for quantifying the variation among samples due to spatial scale and level of wave exposure. Randomly placed $50 \times 50 \mathrm{~cm}$ squares were deployed in shallow rocky-reefs to assess community structure and dominance. Non-parametric multivariate techniques, as well as univariate tests, provided evidence to collectively suggest that shallow water algal assemblages differed between protected (leeward) and exposed (windward) shores, with a consistency of effects across islands, while different spatial scales were also involved in the variability and patchiness of these assemblages. In this sense, differences were clearly taxon and/or group-specific. In general, the presence and abundance of frondose fucoid species was greater on exposed shores than on protected shores, whereas turfalgae dominated along the protected shores of each island. Dissimilarities between islands with regard to the overall algal assemblage generally increased with the distance between islands. In particular, the presence and abundance of fucoid species was greater in the eastern islands, while turf and bush-like algae increased in the western islands. The large-scale gradient of the oceanographic conditions in an east-to-west direction across the Canarian Archipelago provided a partial explanation for this observation although some inconsistencies were observed in the overall regional pattern.
\end{abstract}

KEY WORDS: Algae $\cdot$ Phytobenthic assemblages $\cdot$ Hierarchical design $\cdot$ Spatial variability $\cdot$ Wave exposure $\cdot$ PERMANOVA $\cdot$ Canary Islands

Resale or republication not permitted without written consent of the publisher

\section{INTRODUCTION}

Differences in environmental conditions play an important role in landscape heterogeneity at different scales ranging from local patchiness to variation along biogeographic gradients (Levin 1992, Tilman \& Kareiva 1997, Fraschetti et al. 2001, 2005, Garrabou et al. 2002). Consequently, linkages across multiple scales are increasingly being considered by ecologists (Brown 1995, Fraschetti et al. 2005). The use of macroecology to reconcile biogeography and ecology has hitherto focused mainly on terrestrial systems (Boero 1999), with rare applications of these concepts to marine habitats (Fraschetti et al. 2001). Most studies have focused on a narrow range of spatial scales in a limited number of habitats (Fraschetti et al. 2005). In this sense, linkages between local geography and ecological features have seldom been considered with respect to the composition, distribution and structure of subtidal assemblages on rocky reefs.

The main biological engineers of temperate rocky reefs are macroalgae (Steneck et al. 2002, Graham 
2004). The existence of algae is influenced by pre-recruitment processes (Hoffmann \& Ugarte 1985, Andrew \& Veijo 1998, Coleman 2003), environmental conditions (e.g. wave exposure) (Santelices 1990, Coleman 2003, Taylor \& Schiel 2003), post-recruitment biotic processes (Underwood \& Jernakoff 1981, Jernakoff 1983, Benedetti-Cecchi \& Cinelli 1994), and physical stress and disturbance (Kennelly 1987, Kendrick 1991). The role played by different processes operating at different scales in the composition, distribution and structure of algal assem-

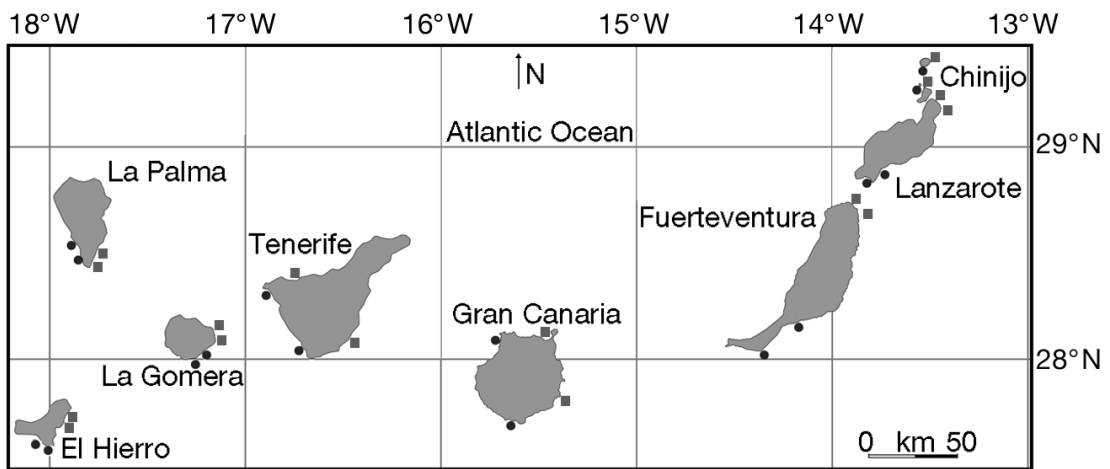

Fig. 1. Study locations within islands. $\bullet$ locations protected from the NE-swell. a: locations exposed to the NE-swell

geneity on the spatial patterns of natural subtidal assemblages (Benedetti-Cecchi et al. 2003, Lindegarth \& Gamfeldt 2005, Micheli et al. 2005). We took advantage of the natural conditions across the Canarian Archipelago to assess the role played by environmental factors in determining the composition, structure and organization of shallow water algal assemblages on rocky reefs. In this sense, we conducted a mensurative, multi-scaled, observational experiment (sensu Underwood 1997, Anderson \& Millar 2004, Fraschetti et al. 2005) to study the effects of: the degree of wave exposure and spatial variability associated with a hierarchy of spatial scales-ranging from (1) islands (100s of $\mathrm{km}$ apart), to (2) locations within islands (10s of $\mathrm{km}$ apart), and (3) sites within locations (100s of $\mathrm{m}$ apart) - on the composition, abundance and distribution of shallow water algal assemblages in a regional context $(<1000 \mathrm{~km})$. More specifically, we tested the hypothesis that the role of wave exposure is significant in determining the structure and organization of shallow water algal assemblages, and assessed the consistency of this pattern across the islands constituting the Canarian Archipelago. Since frondose fucoid algae may be considered as temperate-water elements of the shallow subtidal zone (Lüning 1990, Steneck et al. 2002), whereas turf and bush-like algae are more common in tropical waters (Lüning 1990), we additionally hypothesized that the presence and abundance of fucoid algae should be greater in the eastern islands, while turf and bush-like algae should increase in the western islands. Algae can be expected to be more susceptible to disturbance by wave action and/or be less able to recover after disturbance, when other factors make the environment stressful. As a result, we predicted that the effects of wave exposure would interact with variability among islands, and that the different algal taxa and/or algal groups would show different patterns in this regard.
Islands have provided valuable systems to test hypotheses about the effect of environmental hetero- 


\section{MATERIALS AND METHODS}

Area of study and sampling design. The study was carried out on basaltic rocky bottoms between 2 and $8 \mathrm{~m}$ deep on the Canarian Archipelago $\left(28^{\circ} \mathrm{N}\right.$, eastern Atlantic Ocean), during March 2005. In this region, the long-spined black sea urchin Diadema antillarum (Philippi) plays a key role in the structure of subtidal rocky reefs (Tuya et al. 2004a), transforming areas previously covered by erect algae to unvegetated substrates. In general, water turbulence inhibits considerably the presence of $D$. antillarum within the first meters of the subtidal throughout the eastern Atlantic (Alves et al. 2001). As a result, the distribution of benthic communities along the bathymetric axis usually shows a clear vertical zonation pattern. Within the shallowest zone, extensive stands of algal assemblages dominate the community, with a scarce presence of $D$. antillarum (densities typically range between 0 and 1 ind. $\mathrm{m}^{-2}$ ). Intensive grazing by $D$. antillarum produces clear interfaces between these shallow water algal stands and deeper areas devoid of vegetation (densities usually range between 2 and 12 ind. $\mathrm{m}^{-2}$, Tuya et al. 2004a). The contribution of other herbivorous fauna to the organization of subtidal reefs is negligible compared to $D$. antillarum (Tuya et al. 2004b). For example, echinoid species such as Paracentrotus lividus or Arbacia lixula are found at low densities across all the Canary Islands, in contrast to the nearby Mediterranean Sea.

Responses of algae to environmental variability are best tested using a functional group approach rather than specific species (Steneck \& Dethier 1994). Fleshy, canopy-forming, algae were categorized into 3 morphological groups, taking into account the algal form groups reported in the literature (Steneck \& Dethier 1994, Fowler-Walker \& Connell 2002, Garrabou et al. 2002, McClanahan et al. 2003), especially those from the nearby Mediterranean (Ruitton et al. 2000), as well as on our own experience. Turf algae (TA) consist of small cushion-shaped and filamentous species, usually $<5 \mathrm{~cm}$ in height, such as Codium spp., Colpomenia sinuosa, Dasycladus vermicularis and, principally, Lobophora variegata. Bush-like algae (BA) are sheet-shaped, jointed non-crustose calcareous and thick, leathery species (e.g. Asparagopsis spp., Corallina elongata, Dyctiota spp., Padina pavonica, Stypocaulon scoparium, Stypopodium zonale, Taonia atomaria, Zonaria tournefortii, etc.), from 1 to $15 \mathrm{~cm}$ in height, which constitute either large algal cushions or thin sheets with mixtures of algal species. Corticated, large, canopy-forming brown macrophytes (BM) are erect, frondose, coarsely branched fucoid species (the genera Cystoseira and Sargassum), usually $>15 \mathrm{~cm}$ in height, and in general forming low diversity algal stands. Understorey algae were excluded from the surveys as their coverage is hard to determinate, and a meticulous investigation of the whole substratum is too timeconsuming. However, crustose coralline algae (e.g. the genera Lithothamnion, Lithophyllum, Neogoniolithon, Titanoderma, etc.) were counted when not overgrown by other algae.

Our sampling design tested the effect of the degree of wave exposure to the dominant, trade wind induced NE swells (categorized as high versus low exposure, i.e. exposed or windward versus protected or leeward shores; see Lindegarth \& Gamfeldt 2005 for a discussion of this topic) around each of the 7 islands constituting the Canary Islands, as well as a group of small islets, the 'Chinijo Archipelago', to the north of Lanzarote (Fig. 1). We selected a total of 32 locations across the Canarian Archipelago as spatial replicates of the 16 defined treatments ( 2 degrees of wave exposure $\times 8$ islands), with 2 locations (10s of $\mathrm{km}$ apart) per treatment (Fig. 1). Exposed locations directly received the prevailing swells and winds from the northeast, whereas protected locations lay to the south, on the opposite side of each island (Fig. 1). Swells from the south are significantly rarer (Martín Ruiz 2001). Additionally, we surveyed 2 randomly selected sites between 10 and $100 \mathrm{~m}$ apart within each location. As a result, a hierarchical, structured, sampling design (sensu Underwood 1997, Fraschetti et al. 2005) provided the framework for quantifying the variation among samples due to 3 spatial scales and 2 levels of wave exposure at a regional scale $(<1000 \mathrm{~km})$.

Sampling and data analysis. At each site, a SCUBAdiver quantified in situ the percent cover of algae in four $50 \times 50 \mathrm{~cm}$ squares $\left(0.25 \mathrm{~m}^{2}\right)$, following pointsquare procedures with a grid of 121 points per square. Squares, several meters apart, were randomly laid out. This is a rapid, non-destructive technique used to assess community structure and dominance of sessile biota (Fowler-Walker \& Connell 2002, McClanahan et al. 2003). Final values for each taxon were expressed as percentages. Taxa present in less than a $4 \%$ cover were omitted. Unidentified filamentous turf consisted principally of red algae belonging to the families Ceramiaceae and Rhodomelaceae.

Hypotheses were tested using multivariate and univariate procedures. To test for differences in the algal community caused by the 2 levels of wave exposure across the hierarchy of spatial scales, we selected non-parametric approaches (Anderson 2001, Anderson \& Millar 2004), and applied a mixed analysis technique by combining the semi-parametric, distance based, Permutational Multivariate Analysis of Variance (PERMANOVA, Anderson 2004), and non-metric multidimensional scaling (MDS) ordination (PRIMER soft- 
ware; Clarke \& Warwick 1994). In both cases, data were transformed to square root and analyses were based on Bray-Curtis dissimilarities. The PERMANOVA incorporated the following factors: (1) 'Wave Exposure' (fixed factor with 2 levels: protected versus exposed), (2) 'Island' (fixed factor with 8 levels corresponding to the 7 islands plus Chinijo Archipelago, and orthogonal to the previous factor), (3) 'Locations' (random factor with 2 levels, nested within the interaction term between 'Islands' and 'Wave exposure') and (4) 'Sites' (random factor with 2 levels, nested within the interaction term between 'Locations', 'Islands' and 'Wave exposure'). PERMANOVA was used to partition variability and provide measures of multivariate variability at different scales in the structured design in a manner analogous to univariate partitioning using ANOVA (Anderson \& Millar 2004, Fraschetti et al. 2005). We applied this technique to the overall community dataset, as well as to each of the 3 defined morphological groups of algae. When appropriate, pairwise a posteriori comparisons were executed using permutations (Anderson 2004).

To visualize multivariate patterns, non-metric MDS ordinations were carried out. The MDS was applied to 3 different scenarios, gradually increasing the complexity of the analysis: First, we analyzed the algal community structure by considering only the 16 established treatments ( 8 islands $\times 2$ levels of wave exposure) by pooling the overall data within each treatment; second, we included replicated locations within each treatment; and third, we included replicated sites within locations for each treatment. Stress values are a measure of goodness of fit of data points in the MDS, and stress equals zero when data are perfectly represented (Clarke \& Warwick 1994). If the stress levels are greater that 0.2 , plots are considered difficult to interpret. Since an acceptable stress value $(<0.14)$ was only obtained for the first scenario, this was the only analysis we used.

The SIMPER procedure (Clarke \& Warwick 1994) was carried out to assess average similarities and dissimilarities within and between treatments, respectively, as well as to identify the contribution of each algal taxon to the differences within and between levels of wave exposure and islands. As a result, prominent taxa contributing to differences between treatments were identified and used in subsequent univariate analyses.

A mixed 4-factor ANOVA univariate model (Underwood 1997) was applied to each of the 3 groups of algae, as well as to the prominent taxa detected by the SIMPER protocol, to test for significant differences attributable to the factors discussed above. Hence, ANOVAs tested the same hypotheses described above for multivariate data, but in a univariate context. When the fac- tor 'Islands' was significant for some of the ANOVAs, pairwise a posteriori Student-Newman-Keuls (SNK) tests were used. Before analysis, the Cochran's test was used to check for homogeneity of variances. Although no transformation rendered homogeneous variances in the majority of cases (Cochran's test, p < 0.01), ANOVA was carried out as it is robust to heterogeneity of variances, particularly for large, balanced experiments (Underwood 1997). The significance level was thus set at 0.01 instead of at 0.05 (Underwood 1997).

Finally, we assessed the geographical affinities in the composition and structure of algal assemblages across the Canarian Archipelago by means of a correlation analysis between the average pairwise dissimilarities matrix among islands for the entire dataset and a pairwise matrix containing the minimum lineal distances (in $\mathrm{km}$ ) between each pair of islands. We used the pairwise average dissimilarities matrix output from both the SIMPER procedure and the PERMANOVA.

\section{RESULTS}

A total of 39 algal taxa were observed in the 256 squares conducted at the 32 study locations (Appendix 1, available at www.int-res.com/articles/ suppl/m311p015_app.pdf). The prominent taxa within the TA were, in decreasing order, Lobophora variegata (40.6\% of 256 squares), unidentified filamentous turf (38.6\%) and Jania spp. (32.4\%). The BA group was mainly dominated by Dyctiota dichotoma (68.7\%), Padina pavonica (31.6\%) and Asparagopsis spp. $(21.9 \%)$. Finally, the BM group was represented by Cystoseira spp. (21.9\%) and Sargassum spp. (11.3\%).

\section{Multivariate analysis}

Multivariate techniques revealed large and significant differences in the composition and structure of the algal community for the different factors. Firstly, the multivariate ANOVA performed on the entire algal dataset (Table 1) detected significant variability at the 3 spatial scales considered in our study: differences between islands, differences between locations within each island and level of wave exposure, and differences between sites at the same location within each island and level of wave exposure ( $p<0.001$, Table 1$)$. Significant variability attributable to differences in the degree of wave exposure was found $(p=0.01$, Table 1); the effect of wave exposure was otherwise consistent across the islands (Table 1 , 'I $\times W^{\prime}$ ', $p>0.05$ ). Secondly, the 2-dimensional MDS (Fig. 2, stress value = 0.09) revealed a separation of the treatments along the ordination diagram, with the eastern islands (Chinijo, 
Table 1. PERMANOVA analysis of the effects of islands (fixed), wave exposure (fixed and orthogonal), locations (random and nested within islands and both levels of wave exposure), and sites (random and nested within locations, islands and levels of wave exposure) on the multivariate algal assemblages. p-values were obtained using 4999 random permutations (perm). I: islands, WE: wave exposure, Lo: location, CH: Chinijo, LZ: Lanzarote, FV: Fuerteventura, GC: Gran Canaria, TF: Tenerife, GO: Gomera, LP: La Palma, EH: El Hierro. Pairwise a posteriori comparisons for turf algae: $\mathrm{EH}>\mathrm{GO}$; $\mathrm{EH}>\mathrm{TF} ; \mathrm{EH}>\mathrm{GC} ; \mathrm{EH}>\mathrm{CH} ; \mathrm{LP}>\mathrm{GO} ; \mathrm{LP}>\mathrm{TF} ; \mathrm{LP}>\mathrm{CH} ; \mathrm{GC}>\mathrm{GO} ; \mathrm{FV}>\mathrm{GO} ; \mathrm{FV}>\mathrm{TF}$

\begin{tabular}{|c|c|c|c|c|c|c|c|c|c|c|c|c|c|}
\hline \multirow{2}{*}{$\begin{array}{l}\text { Source of } \\
\text { variation }\end{array}$} & \multirow[t]{2}{*}{ df } & \multicolumn{3}{|c|}{ Overall algal dataset } & \multicolumn{3}{|c|}{ Brown macrophytes } & \multicolumn{3}{|c|}{ Turf algae } & \multicolumn{3}{|c|}{ Bush-like algae } \\
\hline & & MS & F & $\mathrm{p}($ perm $)$ & MS & $F$ & $\mathrm{p}($ perm $)$ & MS & F & $\mathrm{p}($ perm $)$ & MS & $F$ & $\mathrm{p}($ perm $)$ \\
\hline I & 7 & 33008.85 & 3.9300 & 0.0002 & 8821.11 & 1.4240 & 0.1900 & 29818.99 & 3.3717 & 0.0010 & 17632.73 & 1.5323 & 0.0230 \\
\hline WE & 1 & 25228.32 & 3.0061 & 0.0124 & 48821.18 & 7.8814 & 0.0010 & 20309.00 & 2.2964 & 0.0480 & 16408.93 & 1.4260 & 0.1810 \\
\hline Locations $(\mathrm{I} \times \mathrm{WE})$ & 16 & 8392.32 & 6.5029 & 0.0002 & 6194.44 & 2.8576 & 0.0010 & 8843.78 & 2.6911 & 0.0010 & 11507.23 & 3.1114 & 0.0010 \\
\hline Sites $($ Lo $(\mathrm{I} \times \mathrm{WE}))$ & 32 & 1290.55 & 2.6304 & 0.0002 & 2167.68 & 2.5944 & 0.0010 & 3286.32 & 1.2498 & 0.0190 & 3698.43 & 1.3257 & 0.0010 \\
\hline $\mathrm{I} \times \mathrm{WE}$ & 7 & 8119.42 & 0.9675 & 0.5264 & 6473.99 & 1.0451 & 0.4220 & 9805.97 & 1.1088 & 0.3290 & 13786.41 & 1.9181 & 0.2020 \\
\hline Residual & 192 & 490.6209 & & & 835.52 & & & 2629.50 & & & 2789.77 & & \\
\hline
\end{tabular}

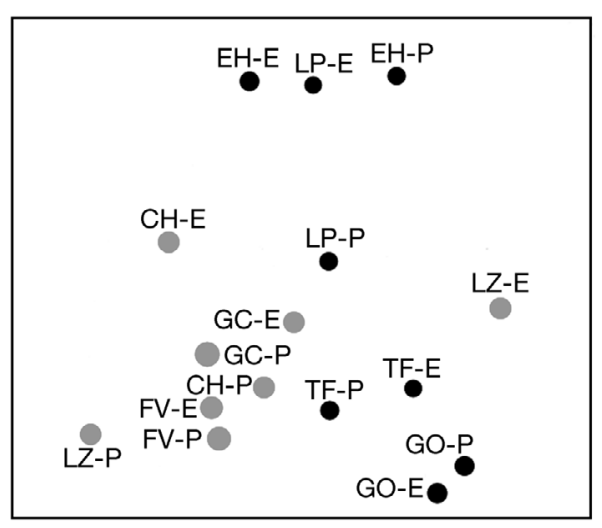

Fig. 2. MDS plot comparing the composition and structure of shallow water algal assemblages for each island and level of wave exposure. P: protected, E: Exposed, CH: Chinijo, LZ: Lanzarote, FV: Fuerteventura, GC: Gran Canaria, TF: Tenerife, GO: Gomera, LP: La Palma, EH: El Hierro. ๑: western islands; : eastern islands

Lanzarote, Fuerteventura and Gran Canaria) falling in the left side of the plot, with the exception of exposed locations in Lanzarote (LZ-E in Fig. 2); whereas the western islands (Tenerife, Gomera, La Palma and El Hierro) were positioned in the right side of the plot.
Several islands (Fuerteventura, Gran Canaria, Tenerife and Gomera) had similar assemblages in both protected and exposed locations, while the rest of the islands showed a clearer distinction between protected and exposed locations in the ordination space (Fig. 2). A posteriori permutational tests among islands revealed a total of 10 significant differences for the 28 possible comparisons ( $\mathrm{p}$ for Monte Carlo $<0.01$ ), with 8 significant differences including El Hierro or La Palma. This result was indicative of the different composition, abundance and structure of the algal assemblages of these 2 islands compared to the rest of the islands. Moreover, the MDS plot also revealed this difference (Fig. 2), with the majority of locations on El Hierro and La Palma positioned at the top of the plot.

However, we found group-specific results when we analyzed the results of the PERMANOVA for each algal group (Table 1). Coverage of the BM group was significantly greater on exposed shores than on protected shores $(\mathrm{p}<0.01$, Table 1$)$ for all islands (Table 2 , Island $\times$ wave exposure ('I $\times W^{\prime}$ '), $\mathrm{p}>0.05$ ); while TA cover differed among islands ( $p<0.01$, Table 1$)$, a finding which was corroborated by some significant pairwise comparisons (Table 1). In all cases, we detected substantial variability at the medium (differ-

Table 2. Analysis of the effects of islands (fixed), wave exposure (fixed and orthogonal), locations (random and nested within islands and both levels of wave exposure), and sites (random and nested within locations, islands and levels of wave exposure) on the mean percent coverage of the 3 algal morphological groups. I: islands, WE: wave exposure, ${ }^{*} p<0.01$. Acronyms for islands as in Table 1. A posteriori SNK tests for turf algae: LP EH GC $>\mathrm{CH}>$ FV GO TF LZ; for bush-like algae: $\underline{\text { LZ FV GC TF }>\text { GO CH LP EH }}$

\begin{tabular}{|c|c|c|c|c|c|c|c|}
\hline \multirow{2}{*}{$\begin{array}{l}\text { Source of } \\
\text { variation }\end{array}$} & \multirow[t]{2}{*}{ df } & \multicolumn{2}{|c|}{ Brown macrophytes } & \multicolumn{2}{|c|}{ Turf algae } & \multicolumn{2}{|c|}{ Bush-like algae } \\
\hline & & MS & $F$ & MS & $F$ & MS & $F$ \\
\hline I & 7 & 0.0777 & 1.58 & 0.2448 & $5.48^{*}$ & 0.3256 & $4.02(p=0.01)$ \\
\hline WE & 1 & 0.5036 & $10.22^{*}$ & 0.4399 & $9.85^{*}$ & 0.0002 & 0.00 \\
\hline Locations $(\mathrm{I} \times \mathrm{WE})$ & 16 & 0.0493 & $8.15^{*}$ & 0.0447 & $5.38^{*}$ & 0.0811 & $18.36^{*}$ \\
\hline Sites (Locations $(\mathrm{I} \times \mathrm{WE}))$ & 32 & 0.0060 & $1.79^{*}$ & 0.0083 & 1.51 & 0.0044 & 1.02 \\
\hline $\mathrm{I} \times \mathrm{WE}$ & 7 & 0.0490 & 0.99 & 0.0620 & 1.39 & 0.0750 & 0.92 \\
\hline Residual & 192 & 0.0034 & & 0.0055 & & 0.0043 & \\
\hline
\end{tabular}


ences between locations) and small (differences between sites) spatial scales ( $\mathrm{p}<$ 0.01, Table 1).

SIMPER analysis indicated that the average similarity among protected locations $(38.46 \%)$ was greater than the average similarity among exposed locations $(28.80 \%)$, suggesting a greater heterogeneity of exposed algal assemblages. Eight taxa contributed extensively to the differences between both levels of wave exposure, accounting for $57.97 \%$ of the overall dissimilarity (Appendix 2, available at www.int-res.com/ articles/suppl/m311p015_app.pdf). In general, these taxa, as well as the fucoids Cystoseira mauritanica and Sargassum spp., accounted for dissimilarities among islands, although the relative importance of each taxon varied for each pair of comparisons (Appendix 2).

Average dissimilarities between pairs of islands were significantly correlated with the lineal distances in $\mathrm{km}$ between them $\left(r_{\mathrm{s}}=0.49,0.001<\mathrm{p}<0.01\right.$ using the results from the SIMPER procedure; $\mathrm{r}_{\mathrm{s}}=$ $0.36,0.01<\mathrm{p}<0.05$ using the results from the PERMANOVA).

\section{Univariate analyses}

Mean percentage covers across the study area (islands, locations within islands, and sites within locations) for 3 defined algal groups: TA, BA and BM are shown in Figs. 3, 4 \& 5, respectively. Results from the ANOVAs performed on the 3 groups are presented in Table 2 . Although the ANOVAs indicated a significant effect of the variability between sites, $10 \mathrm{~s}$ of $\mathrm{m}$ apart, within locations for the BM only, we detected substantial spatial heterogeneity at the medium spatial scale (differences between locations, 10s of km apart, within each island and level of wave exposure) for the 3 morphological groups ( $p<$ 0.01 , Table 2). This considerable variability prevented the detection of significant differences caused by some of the 2 main effects in the 3 ANOVAs. However, the power of the ANOVAs was sufficient to reject some null hypotheses. In this sense, the BM group was significantly more abundant on exposed shores ( $p<0.01$, Table 2, Fig. 5), whereas the TA group was more abundant on protected shores $(\mathrm{p}<$ 0.01, Table 2, Fig. 3). In both cases, the effect of the
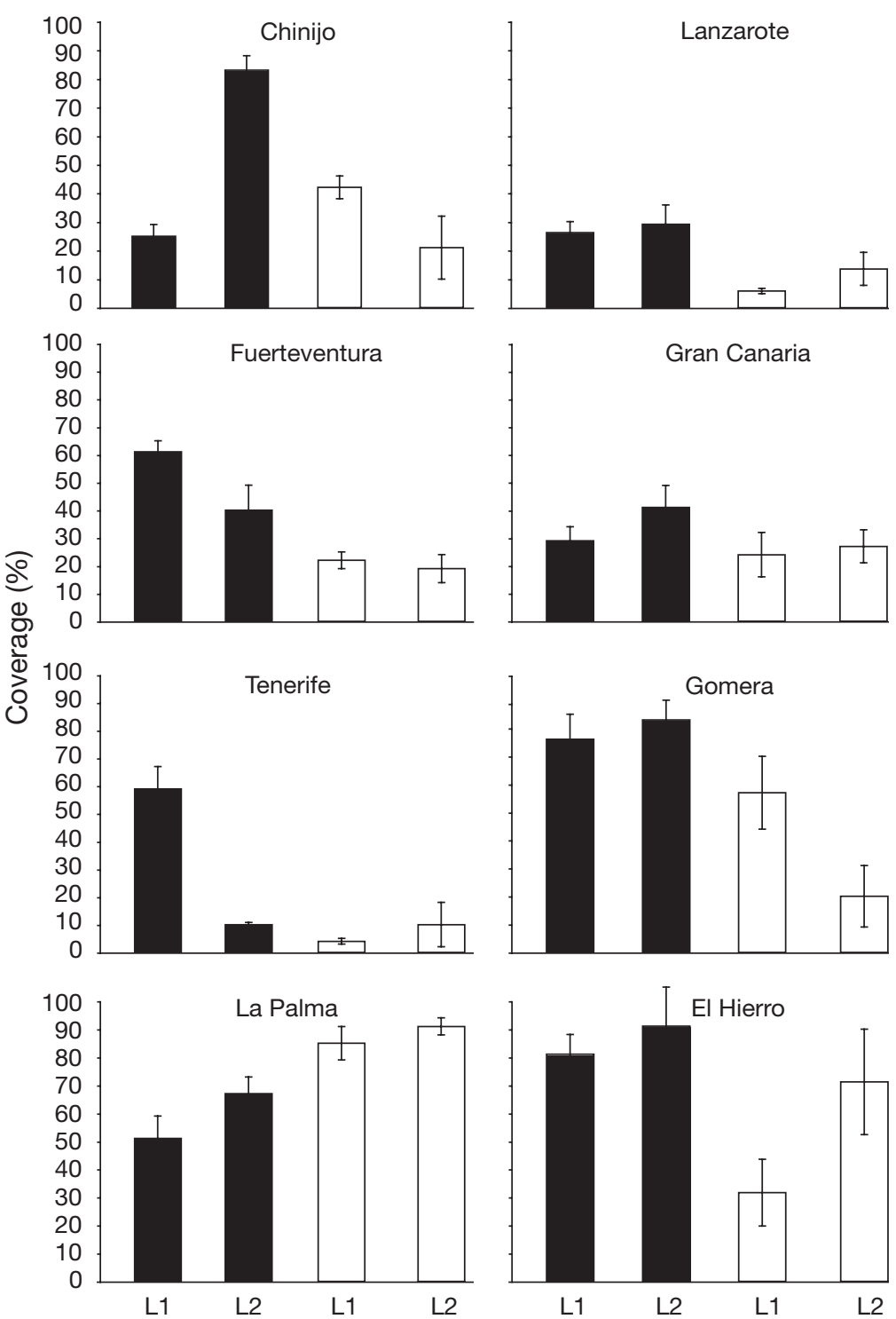

Fig. 3. Turf algae. Mean percentage cover across the study area. Black bars: protected locations (L1 and L2), white bars: exposed locations (L1 and L2). Error bars are mean $\pm \mathrm{SE}$

'wave exposure' was consistent across the islands (Table 2, 'I $\times W^{\prime}$ ', $p>0.05$ ). Significant differences caused by the different islands were not detected for BM ( $p>0.01$, Table 2), although visual inspection of the results (Fig. 5) suggests the existence of differences. In contrast, significant differences caused by 'Islands' were detected for TA ( $p<0.01$, Table 2) and BA ( $\mathrm{p}=0.01$, Table 2), and can be seen in Figs. 3 \& 4. A posteriori SNK tests (Table 2) indicated that the TA group dominated the western islands, whereas BA dominated the central and eastern islands, with the exception of Chinijo Archipelago.

Results from the ANOVAs performed on the prominent algal taxa are presented in Table 3. Again, the 


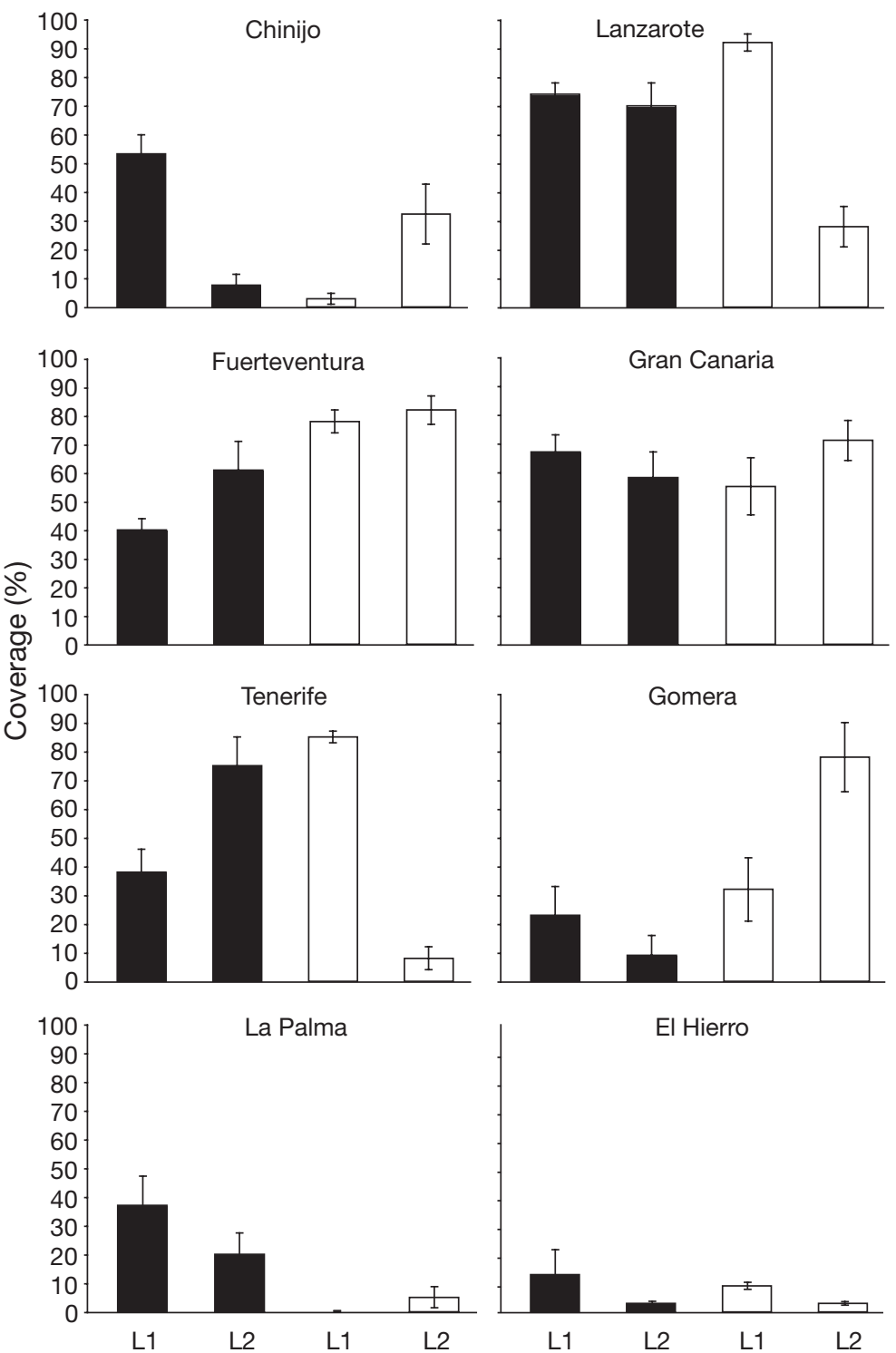

Fig. 4. Bush-like algae. Mean percentage cover across the study area. Black bars: protected locations (L1 and L2), white bars: exposed locations (L1 and L2). Error bars are mean $\pm \mathrm{SE}$

SNK tests, Table 3). Jania spp. (Fig. 7) appeared to be more abundant in the eastern islands ( $\mathrm{p}<0.01$, SNK tests, Table 3$)$. Finally, the unidentified filamentous turf (Fig. 8) was significantly more abundant in Gomera and Tenerife than in the rest of the islands ( $p<0.01$, SNK tests, Table 3$)$.

\section{DISCUSSION}

The presence of multiple islands along an oceanographic gradient with shores exposed to different hydrographic conditions provided an ideal opportunity to test hypotheses about the individual and combined effects of geographical and physical processes on entire subtidal shallow water algal assemblages. Collectively, the findings of this study showed that subtidal algal assemblages differ consistently between protected and exposed shores across the surveyed islands. Additionally, clear differences were observed between islands situated on opposite sides of the Canarian Archipelago.

The analysis of pattern in distribution and abundance of marine organisms has direct relevance to the identification of underlying causal processes (Benedetti-Cecchi et al. 2003 and references therein, Fraschetti et al. 2005). Biotic processes and behavior are usually implicated in the maintenance of small to medium scale spatial patchiness (e.g. differences between sites and locations separated by 100s of $\mathrm{m}$ to $10 \mathrm{~s}$ of $\mathrm{km}$ ), whereas oceanographic conditions and climate largely dictate regional, large-scale patterns operating over distances of 100s of $\mathrm{km}$ (Underwood \& Chapman 1996, Menconi et al. 1999). Our

analyses indicated substantial variability at the medium and low spatial scales (differences between locations $10 \mathrm{~s}$ of $\mathrm{km}$ apart within each island and level of wave exposure, and between sites $10 \mathrm{~s}$ of $\mathrm{m}$ apart within locations, respectively). Due to the variability between locations within each treatment, significant differences were only found between islands and between levels of wave exposure for Lobophora variegata, Jania spp., and the unidentified filamentous turf (Figs. 6, $7 \&$ 8, respectively). L. variegata (Fig. 6) monopolized the rocky bottoms of both El Hierro and La Palma with mean percent coverages of up to $90 \%$ per location, and was significantly more abundant in these islands than in all other islands $(p<0.01$, results support, in part, these conclusions. In particular, certain important group-specific differences within islands can be attributed to differences in levels of wave exposure, while significant differences at a regional scale (differences between islands 100s of $\mathrm{km}$ apart) were found for some groups and taxa.

\section{Variability associated with differences in the level of wave exposure}

The combined indirect and direct hydrodynamic effects of wave action on nearshore biota are often grouped under the term 'wave exposure' (Taylor \& 

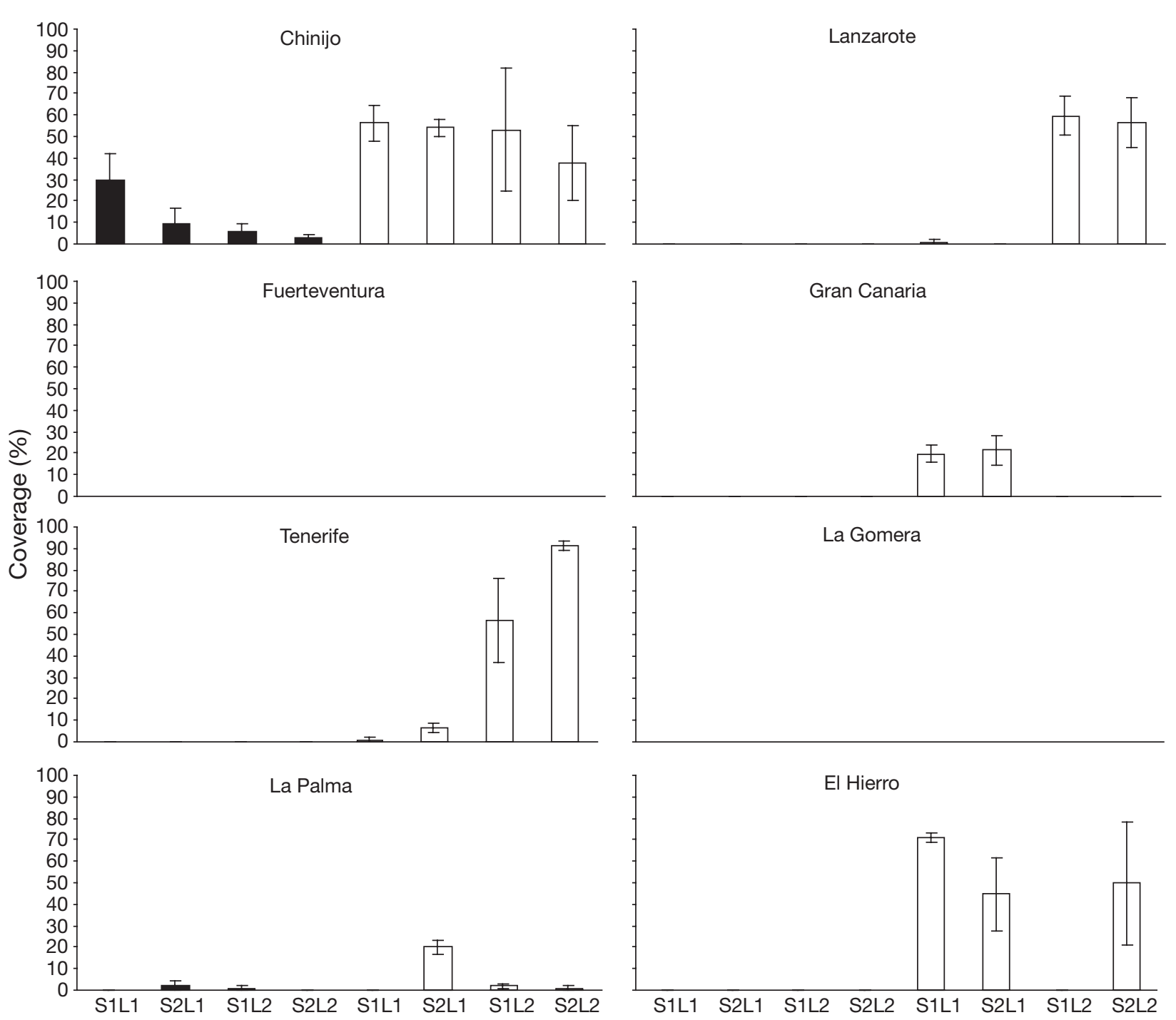

Fig. 5. Brown macrophytes. Mean percentage cover across the study area. Black bars: sites within protected locations (e.g. S1L1 denotes site 1 within location 1), white bars: sites within exposed locations. Error bars are mean $\pm \mathrm{SE}$

Schiel 2003). Distinct patterns arose when the results of our study on the effect of 'wave exposure' were interpreted at a morphological group level. In general, the presence and abundance of species within the BM group (frondose fucoid species) was clearly greater at exposed locations (mean coverage for all exposed locations $=22.00 \pm 5.61$, mean $\pm \mathrm{SE}$ ) compared to protected locations (mean coverage for all protected locations = $1.56 \pm 1.07$, mean $\pm \mathrm{SE}$ ). Subtidal fucoid plants tend to be better adapted to exposed or semi-exposed conditions than other algal species in the Canary Islands (Medina \& Haroun 1993, Haroun et al. 2003).

However, the ecological mechanisms underlying this difference are unknown. Variation in hydrographic conditions at the scales considered by our sampling design probably influence algal assemblages through the temporal variability and intensity of swells and storms, and the release of propagules from the water column (Micheli et al. 2005). Usually, water motion (1) enhances nutrient uptake by reducing or breaking the boundary layer, (2) removes epiphytes and waste products, and (3) allows algal stands to use light more efficiently by stirring their fronds, ensuring that no frond is either always shaded or always in the sun (Diez et al. 2003 and references therein). These mechanical advantages are accompanied by a continued mechanical stress that only morphologically adapted species can resist. Algae in these disturbed environments are characterized by a flexible thallus and an efficient attachment mechanism, such as the basal disc of certain species belonging to the genera Cystoseira and Sargassum. 
Table 3. Analysis of the effects of islands (fixed), wave exposure (fixed and orthogonal), locations (random and nested within islands and both levels of wave exposure), and sites (random and nested within locations, islands and levels of wave exposure) on the mean percent of coverage of selected algal species. Acronyms for islands as in Table 1. I: islands, WE: wave exposure ${ }^{*} \mathrm{p}<0.01$. A posteriori SNK tests for Lobophora variegata: $\underline{\mathrm{EH}} \mathrm{LP}>\mathrm{GC}>\underline{\mathrm{CH}} \mathrm{FV}$ LZ TF GO ; for unidentified filamentous turf:

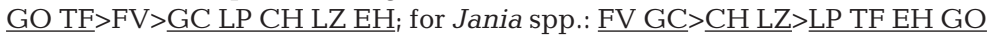

\begin{tabular}{|c|c|c|c|c|c|c|c|c|c|c|c|}
\hline \multirow{2}{*}{$\begin{array}{l}\text { Source of } \\
\text { variation } \\
\text { I }\end{array}$} & \multirow{2}{*}{$\begin{array}{l}\mathrm{df} \\
7\end{array}$} & \multicolumn{2}{|c|}{$\begin{array}{l}\text { MS Fobophora } \\
\text { variegata }\end{array}$} & \multicolumn{2}{|c|}{$\begin{array}{c}\text { MS } \quad F \\
\text { Unidentified } \\
\text { filamentous turf }\end{array}$} & \multicolumn{2}{|c|}{$\begin{array}{l}\text { MS F } \\
\text { Dyctiota } \\
\text { dichotoma }\end{array}$} & \multicolumn{2}{|c|}{$\begin{array}{l}\text { MS F F } \\
\text { Stypocaulon } \\
\text { scoparium }\end{array}$} & \multicolumn{2}{|c|}{$\begin{array}{c}\text { MS } \quad F \\
\text { Asparagopsis } \\
\text { spp. }\end{array}$} \\
\hline & & 40.1578 & $23.88^{*}$ & 16.8451 & $4.80^{*}$ & 13.1876 & 3.63 & 0.0385 & 1.29 & 4.2593 & 3.42 \\
\hline WE & 1 & 3.1696 & 1.88 & 51.8169 & $14.77^{*}$ & 0.7873 & 0.22 & 0.0078 & 0.26 & 0.1253 & 0.10 \\
\hline Locations $(\mathrm{I} \times \mathrm{WE})$ & 16 & 1.6819 & $5.30^{*}$ & 3.5074 & $4.52^{*}$ & 3.6322 & $15.84^{*}$ & 0.0298 & $22.05^{*}$ & 1.2458 & 1.27 \\
\hline Sites (Locations $(\mathrm{I} \times \mathrm{WE}))$ & 32 & 0.3174 & 1.25 & 0.7758 & $2.26^{*}$ & 0.2293 & 0.86 & 0.0014 & 1.16 & 0.9833 & $4.51^{*}$ \\
\hline $\mathrm{I} \times \mathrm{WE}$ & 7 & 3.0250 & 1.80 & 1.5045 & 0.43 & 1.6675 & 0.46 & 0.0240 & 0.81 & 3.1134 & 2.50 \\
\hline \multirow[t]{2}{*}{ Residual } & 192 & 0.2546 & & 0.3435 & & 0.2680 & & 0.0012 & & 0.2178 & \\
\hline & & \multicolumn{2}{|c|}{$\begin{array}{l}\text { Jania } \\
\text { spp. }\end{array}$} & \multicolumn{2}{|c|}{$\begin{array}{c}\text { Padina } \\
\text { pavonica }\end{array}$} & \multicolumn{2}{|c|}{$\begin{array}{c}\text { Cystoseira } \\
\text { abies-marina }\end{array}$} & \multicolumn{2}{|c|}{$\begin{array}{c}\text { Cystoseira } \\
\text { mauritanica }\end{array}$} & \multicolumn{2}{|c|}{$\begin{array}{c}\text { Sargassum } \\
\text { spp. }\end{array}$} \\
\hline I & 7 & 4.9245 & $6.02^{*}$ & 3.3948 & 1.27 & 0.1150 & 0.95 & 0.0164 & 1.62 & 0.0325 & 2.11 \\
\hline WE & 1 & 1.6889 & 2.06 & 2.6661 & 1.00 & 0.3494 & 2.90 & 0.0038 & 0.38 & 0.0627 & 4.07 \\
\hline Locations $(\mathrm{I} \times \mathrm{WE})$ & 16 & 0.8180 & $3.77^{*}$ & 2.6696 & $28.64^{*}$ & 0.1206 & $31.14^{*}$ & 0.0101 & $7.95^{*}$ & 0.0154 & $4.91 *$ \\
\hline Sites (Locations $(I \times W E)$ ) & 32 & 0.2167 & 1.29 & 0.0932 & 1.11 & 0.0039 & $2.03^{*}$ & 0.0013 & 0.98 & 0.0031 & $2.27^{\star}$ \\
\hline $\mathrm{I} \times \mathrm{WE}$ & 7 & 0.9106 & 1.11 & 1.1227 & 0.42 & 0.1150 & 0.95 & 0.0038 & 0.38 & 0.0243 & 1.58 \\
\hline Residual & 192 & 0.1679 & & 0.0839 & & 0.0019 & & 0.0013 & & 0.0014 & \\
\hline
\end{tabular}

Alternatively, this pattern could be related to anthropogenic perturbations. There is an increasing trend towards long-term, and perhaps permanent, loss of canopy-forming algae along human-impacted coasts (Russell \& Connell 2005 and references therein). The loss of canopy-forming algae typically results in the immediate colonisation and spatial dominance of turf algae (Russell \& Connell 2005). In this context, Benedetti-Cecchi et al. (2001) found that frondose, coarsely-branched algae were virtually absent from urban areas in the Mediterranean, having been replaced by turf-forming algae. These authors argued that this group of fucoid algae (e.g. the genus Cystoseira) is highly sensitive to human disturbances. In the Canarian Archipelago, the most important urban areas associated with the tourist industry are located on the protected southern shores of each island (Martin-Ruiz 2001). As a result, the large number of sewage discharges, and subsequently the nutrient enrichment, along these human-disturbed areas could be one reason for the lack of BM in the protected locations of our study. It is possible that a combination of wave action and anthropogenic disturbance is important in this variability within each island. However, the lack of historical data on these assemblages and of any direct quantification of the intensity and distribution of disturbances on the islands make it impossible to conclusively link these observed patterns to human impacts.
The pattern detected for the BM group clearly contrasts with that observed for TA, and in particular, for the patterns observed for the unidentified filamentous turf group. As a general pattern, TA dominated protected locations within each island, with the exception of La Palma. For example, the unidentified filamentous turf group was twice as abundant in protected locations (coverage for all protected locations $=20.84 \pm 5.70$, mean $\pm \mathrm{SE}$ ) as in exposed locations (coverage for all exposed locations $=10.37 \pm 4.03$, mean $\pm \mathrm{SE}$ ) for the overall study. Consequently, our observations reinforce the findings of other investigations that have highlighted the important role played by wave exposure in shaping shallow marine benthic communities in temperate waters (Blanchette et al. 1999, Benedetti-Cecchi et al. 2003, Taylor \& Schiel 2003, Lindegarth \& Gamfeldt 2005, Micheli et al. 2005).

\section{Variability at the medium and small spatial scale: differences within islands}

In all cases analyzed by means of the multivariate ANOVAs, sampled locations within each island and level of wave exposure, as well as sites within locations, were quantitatively different. Considerable heterogeneity at these spatial scales highlights the complex nature of these assemblages; small-scale vari- 

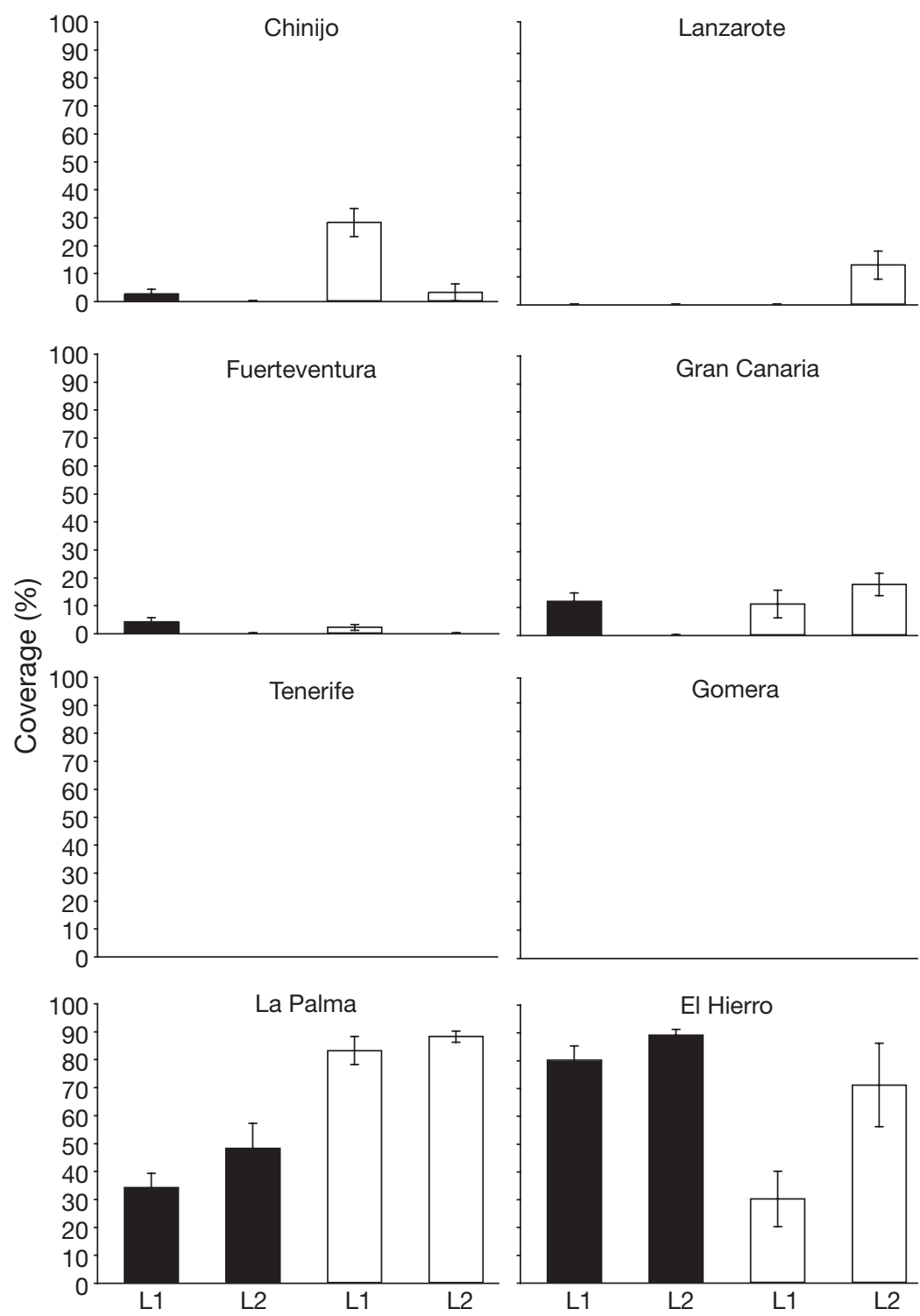

Fig. 6. Lobophora variegata. Mean percentage cover across the study area. Black bars: protected locations (L1 and L2), white bars: exposed locations (L1 and L2). Error bars are mean $\pm \mathrm{SE}$ physical (e.g. availability of resources, habitat attributes) and biological processes (e.g. competition, predation). Clearly, different explanations can be proposed for different taxa, according to their life-history strategies and biology.

\section{Variability at the large spatial scale: differences between islands}

Dissimilarities between islands for the overall subtidal algal community generally increased with the distance between islands. For example, El Hierro and La Palma, the westernmost islands, constituted a different assemblage 'block' from the rest of the islands. However, significant differences between islands were group, or more specifically, taxon-specific.

What are the underlying mechanisms that could account for differences between islands? Generally, differences in patterns of water circulation, availability of resources and type of substratum affecting recruitment, growth and mortality of algae have been proposed as explanations of variability at large spatial scales (from 10s to $100 \mathrm{~s}$ of $\mathrm{km}$ ) (Santelices 1990, Menconi et al. 1999). The large-scale gradient in oceanographic conditions, such as SST and nutrients, in an east-to-west direction across the Canarian Archipelago (Barton et al. 1998, Bode et al. 2001, Davenport et al. 2002) provides a possible explanation for this observation. Variation in oceanographic conditions usually results in differences in local productivity potential, which, in turn, can result in a visible and predictable change in the algal community (Steneck \& Dethier 1994). In this context, our results agree with those of Schils and

ability is a general property of benthic assemblages in marine coastal habitats (Underwood \& Chapman 1996, Menconi et al. 1999, Benedetti-Cecchi 2001, FowlerWalker \& Connell 2002, Benedetti-Cecchi et al. 2003, Coleman 2003, Fraschetti et al. 2005). Differences between locations within each island and level of wave exposure were often as great as differences among islands or level of wave exposure. For some algal groups and taxa, variability at the location level probably obscured differences in cover between levels of wave exposure and islands. We can only speculate on the underlying causes of this variation, which are likely to involve complex interactions among several Coppejans (2003), who attributed differences in the composition, abundance and structure of subtidal algal communities in the Socotra Archipelago, Indian Ocean, to differences in SSTs and bottom-up resources caused by upwelling. The drawback of this approach is that islands may differ in other respects than differences in bottom-up availability of resources. Hence, caution is necessary in ascribing differences in the observed algal assemblages; causality can only be determined through experimental manipulation (Dulvy et al. 2004).

We hypothesized that the presence and abundance of fucoid species should be larger in the eastern 


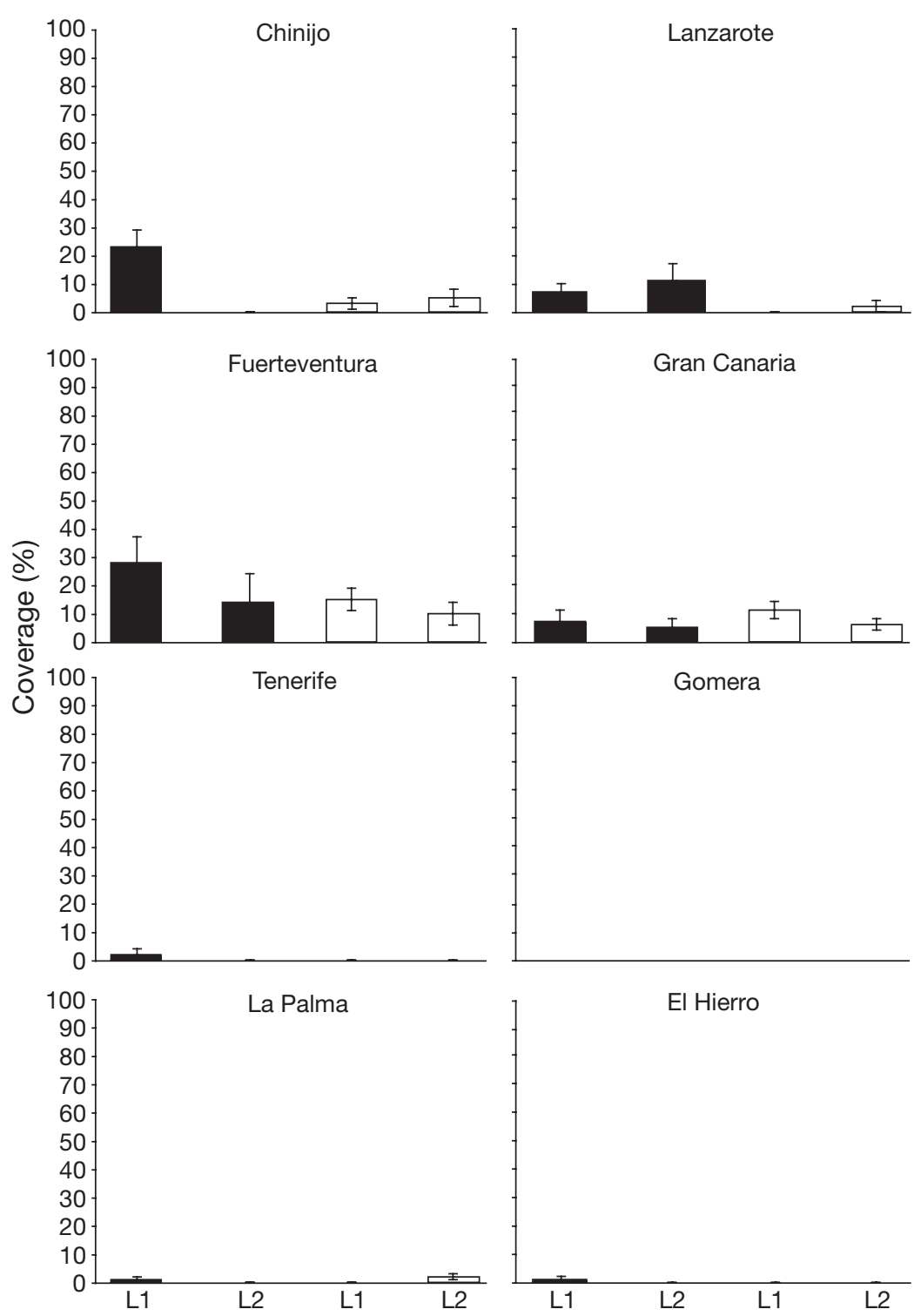

Fig. 7. Jania spp. Mean percentage cover across the study area. Black bars: protected locations (L1 and L2), white bars: exposed locations (L1 and L2). Error bars are mean \pm SE

islands, where SSTs are about $2^{\circ} \mathrm{C}$ lower than in the western islands, while the TA and BA groups should increase in the western islands. Our results generally support this pattern. For example, the fucoid alga Cystoseira mauritanica was only recorded at Chinijo Archipelago; whereas turf algae, and particularly Lobophora variegata, were most abundant in the westernmost islands (El Hierro and La Palma). This result is consistent with the composition and structure of populations of the genus Cystoseira across subtidal and intertidal habitats of the Canarian Archipelago (Medina et al. 1995, Haroun \& Afonso-Carrillo 1997). Nevertheless, we found some inconsistencies in this general pattern. For example, no fucoid species (BM) were observed in Fuerteventura, while this algal group was relatively abundant in the westernmost island (El Hierro). The origin of the potential mechanisms explaining the 'temperate vs. tropical' differences in algal assemblages is unknown, though differences in the availability of 'bottom-up' resources apparently play an important role in explaining such differences. More work is desirable to empirically assess the reasons for this pattern.

Consequently, a generalization of patterns and the establishment of a regional framework for the composition, abundance and distribution of shallow water algal assemblages along the entire Canarian Archipelago is complicated. Many environmental factors co-vary across large spatial gradients (Harley et al. 2003), making temperate rocky reef assemblages highly variable and dynamic at a regional scale (Micheli et al. 2005). Within-island variability also obscures the hypothesized regional pattern. As a result, increasing the spatial replication at the smallest spatial scales (replicated squares within sites, and sites within locations) would probably help to decrease the 'noise' associated with other sources of environmental variability. It is difficult to understand the generality of patterns in algal assemblages using a hierarchy of spatial scales covering $<1000 \mathrm{~km}$ (FowlerWalker \& Connell 2002). We therefore suggest increasing the spatial scale of observation $(>1000 \mathrm{~km}$ ) to encompass a wider area of study along the warmtemperate waters of the eastern Atlantic in the northern hemisphere. This approach would probably provide evidence of the existence of simple underlying rules (sensu Fowler-Walker \& Connell 2002, Fraschetti et al. 2005) in the organization of shallow water algal assemblages.

Acknowledgements. We thank I. Blanch for help with the underwater collection of data. Dr. T. Dempster significantly improved previous drafts with his English editing, while comments by 3 anonymous reviewers significantly improved the manuscript. Financial support was provided by the EU INTERREG-IIIB initiative in the frameworks of the MARMAC and PARMAR projects. 


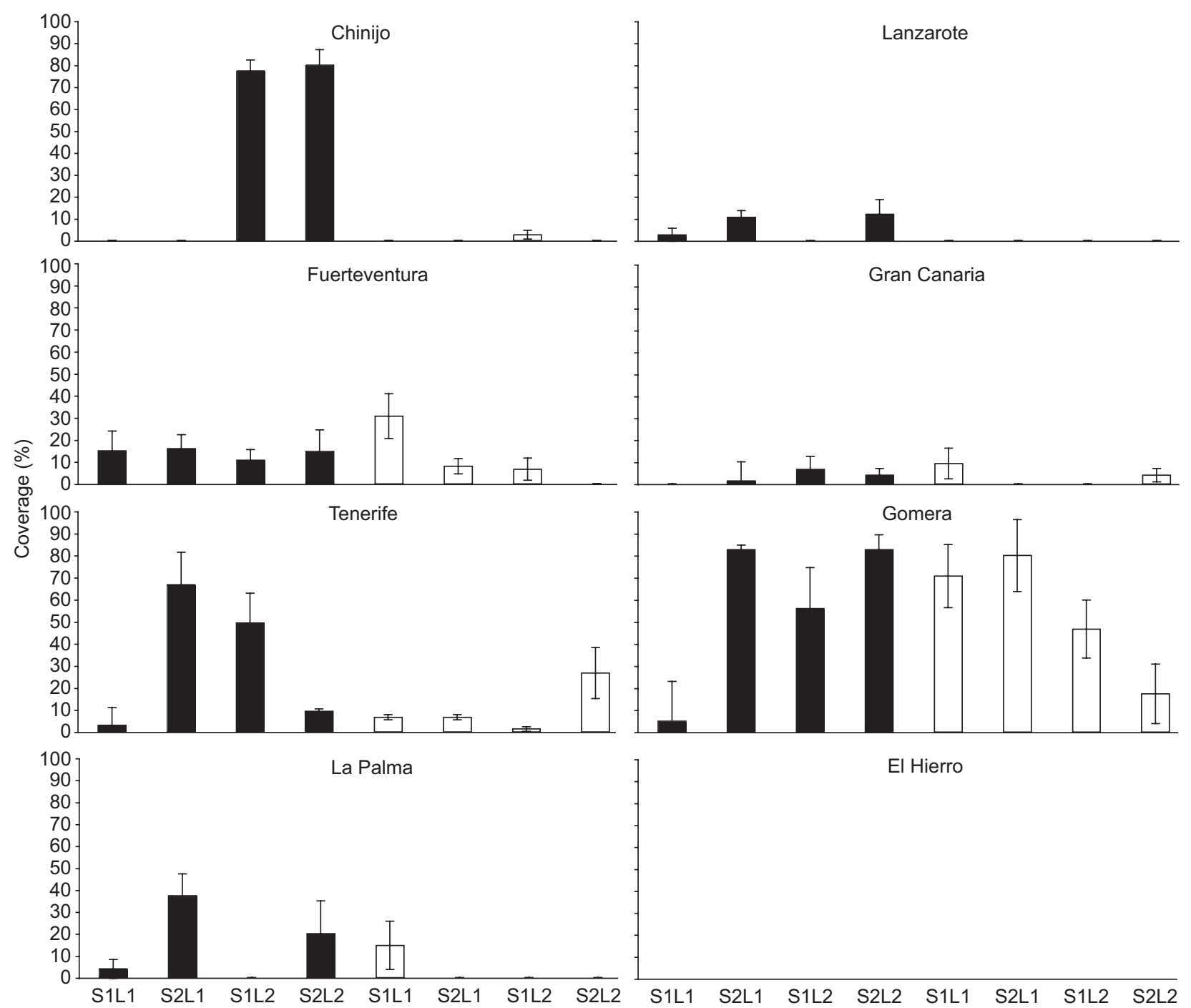

Fig. 8. Unidentified filamentous turf (red algae belonging to the families Ceramiaceae and Rhodomelaceae). Mean percentage cover across the study area. Black bars: sites within protected locations (e.g. S1L1 denotes site 1 within location 1), white bars: sites within exposed locations. Error bars are mean $\pm \mathrm{SE}$

\section{LITERATURE CITED}

Alves FMA, Chicharo LM, Serrao E, Abreu AD (2001) Algal cover and sea urchin spatial distribution at Madeira Island (NE Atlantic). Sci Mar 65:383-392

Anderson MJ (2001) A new method for non-parametric multivariate analysis of variance in ecology. Aust Ecol 26:32-46

Anderson MJ (2004) PERMANOVA_2factor: a FORTRAN computer program for permutational multivariate analysis of variance (for any 2-factor ANOVA design) using permutation tests. Department of Statistics, University of Auckland

Anderson MJ, Millar RB (2004) Spatial variation and effects of habitat on temperate reef assemblages in north eastern New Zealand. J Exp Mar Biol Ecol 305:191-221

Andrew NL, Veijo RM (1998) Ecological limits to invasion of Sargassum muticum in northern Spain. Aquat Bot 60: 251-263

Barton ED, Arístegui J, Tett P, Cantón M and 18 others (1998)
The transition zone of the Canary Current upwelling region. Prog Oceanogr 41:455-504

Benedetti-Cecchi L (2001) Variability in abundance of algae and invertebrates at different spatial scales on rocky sea shores. Mar Ecol Prog Ser 215:79-92

Benedetti-Cecchi L, Cinelli F (1994) Recovery of patches in an assemblage of geniculate coralline algae: variability at different succesional stages. Mar Ecol Prog Ser 110:9-18

Benedetti-Cecchi L, Pannacciulli F, Bulleri F, Moschella PS, Airoldi L, Relini G, Cinelli F (2001) Predicting the consequences of anthropogenic disturbances: large-scale effects of loss of canopy algae on rocky shores. Mar Ecol Prog Ser 214:137-150

Benedetti-Cecchi L, Maggi E, Bertocci I, Vaselli S, Micheli F, Osio GC, Cinelli F (2003) Variation in rocky shore assemblages in the northwestern Mediterranean: contrasts between islands and the mainland. J Exp Mar Biol Ecol 293:193-215

Blanchette CA, Thornber C, Gaines S (1999) Effects of wave 
exposure on intertidal fucoid algae. Proc Calif Islands Symp 5:347-355

Bode A, Barquero S, Varela M, Braun JG, De Armas D (2001) Pelagic bacteria and phytoplankton in oceanic waters near the Canary Islands in summer. Mar Ecol Prog Ser 209:1-17

Boero F (1999) Macroecology returns. J Evol Biol 12:999-1001

Brown JH (1995) Macroecology. University of Chicago Press, Chicago

Clarke KR, Warwick RM (1994) Change in marine communities: an approach to statistical analysis and interpretation. Natural Environment Research Council, Plymouth

Coleman MA (2003) The role of recruitment in structuring patterns of small-scale spatial variability in intertidal and subtidal algal turfs. J Exp Mar Biol Ecol 291:131-145

Davenport R, Never S, Helmke P, Perez-Moreno J, Llinás O (2002) Primary productivity in the northern Canary Islands region as inferred from Seawifs imagery. Deep-Sea Res II 49:3481-3496

Dethier MN, Schoch GC (2005). The consequences of scale: assessing the distribution of benthic populations in a complex estuarine fjord. Estuar Coast Shelf Sci 62:253-270

Diez I, Santolaria A, Gorostiaga JM (2003) The relationship of environmental factors to the structure and distribution of subtidal seaweed vegetation of the western Basque coast (N Spain). Estuar Coast Shelf Sci 56:1041-1054

Dulvy NK, Freckleton RP, Polunin NVC (2004) Coral reef cascades and the indirect effects of predator removal by exploitation. Ecol Lett 7:410-416

Fowler-Walker MJ, Connell SD (2002) Opposing states of subtidal habitat across temperate Australia: consistency and predictability in kelp canopy-benthic associations. Mar Ecol Prog Ser 240:49-56

Fraschetti S, Bianchi CN, Terlizzi A, Fanelli G, Morri C, Boero F (2001) Spatial variability and human disturbances in shallow subtidal hard substrate assemblages: a regional approach. Mar Ecol Prog Ser 212:1-12

Fraschetti S, Terlizzi A, Benedetti-Cecchi L (2005) Patterns of distribution of marine assemblages from rocky shores: evidence of relevant scales of variation. Mar Ecol Prog Ser 296:13-29

Garrabou J, Ballesteros E, Zabala M (2002) Structure and dynamics of north-western Mediterranean rocky benthic communities along a depth gradient. Estuar Coast Shelf Sci 55:493-508

Graham MH (2004) Effects of local deforestation of the diversity and structure of southern California giant kelp forest food webs. Ecosystems 7:341-357

Harley CDG, Smith KF, Moore VL (2003) Environmental variability and biogeography: the relationship between bathymetric distribution and geographical range size in marine algae and gastropods. Glob Ecol Biogeogr 12:499-506

Haroun RJ, Afonso-Carrillo A (1997) Flora marina de Canarias y su biodiversidad In: Pérez de Paz P (ed) Ecosistemas Insulares Canarios. Usos y aprovechamientos en el territorio. Consejería de Política Territorial, Gobierno de Canarias, p 163-168

Haroun R, Gil-Rodríguez MC, Wildpret de la Torre W (2003) Plantas marinas de Canarias. Canseco Press, Talavera

Hoffman AJ, Ugarte R (1985) The arrival of propagules of marine macroalgae in the intertidal zone. J Exp Mar Biol Ecol 92:83-95

Jernakoff P (1983) Factors affecting the recruitment of algae in a midshore region dominated by barnacles. J Exp Mar Biol Ecol 67:17-32

Kendrick GA (1991) Recruitment of coralline crusts and filamentous turf algae in the Galapagos Archipelago: effect of simulated scour, erosion and accretion. J Exp Mar Biol Ecol 147:47-63

Kennelly SJ (1987) Physical disturbance in an Australian kelp community: 1. Temporal effects. Mar Ecol Prog Ser 40: 145-153

Levin SA (1992) The problem of pattern and scale in ecology. Ecology 73:1943-1967

Lindegarth M, Gamfeldt L (2005) Comparing categorical and continuous ecological analyses: effects of 'wave exposure' on rocky shores. Ecology 86:1346-1357

Lüning K (1990) Seaweeds: their environment, biogeography, and ecophysiology. Wiley, New York

Martín Ruiz JF (2001) Geografía de Canarias. Sociedad y medio natural. Ediciones del Cabildo de Gran Canaria, Las Palmas

McClanahan TR, Sala E, Stickels PA, Cokos BA, Baker AC, Starger CJ, Jones IV SH (2003) Interaction between nutrients and herbivory in controlling algal communities and coral condition on Glover's Reef, Belize. Mar Ecol Prog Ser 261:135-147

Medina M, Haroun RJ (1993) Preliminary study on the dynamics of Cystoseira abies-marina populations on Tenerife (Canary Islands). Cour Forschungsinst Senckenb: 109-112

Medina M, Haroun RJ, Wildpret W (1995) Phytosociological study of the Cystoseira abies-marina community in the Canarian Archipelago. Bol Mus Munic Funchal 4: 433-439

Menconi M, Benedetti-Cecchi L, Cinelli F (1999) Spatial and temporal variability in the distribution of algae and invertebrates on rocky shores in the northwest Mediterranean. J Exp Mar Biol Ecol 233:1-23

Menge BA (2000) Top-down and bottom-up community regulation in marine rocky intertidal habitats. J Exp Mar Biol Ecol 250:257-289

Micheli F, Benedetti-Cecchi L, Gambaccini S, Bertocci I, Borsini C, Chato Osio G, Romano F (2005) Cascading human impacts, marine protected areas, and the structure of Mediterranean reef assemblages. Ecol Monogr 75:81-102

Ruitton S, Francour P, Boudouresque CF (2000) Relationships between algae, benthic herbivorous invertebrates and fishes in rocky sublittoral communities of a temperate sea (Mediterranean). Estuar Coast Shelf Sci 50:217-230

Russell BD, Connell SD (2005) A novel interaction between nutrients and grazers alters relative dominance of marine habitats. Mar Ecol Prog Ser 289:5-11

Santelices B (1990) Patterns of reproduction, dispersal and recruitment in seaweeds. Oceanogr Mar Biol Annu Rev 28:177-276

Schils T, Coppejans E (2003) Spatial variation in subtidal plant communities around the Socorra Archipelago and their biogeographic affinities within the Indian Ocean. Mar Ecol Prog Ser 251:103-114

Steneck RS, Dethier MN (1994) A functional group approach to the structure of algal-dominated communities. Oikos 69:476-498

Steneck RS, Graham MH, Bourque BJ, Corbett D, Erlandson JM, Estes JA, Tegner MT (2002) Kelp forest ecosystems: biodiversity, stability, resilience and future. Environ Conserv 29:436-459

Taylor DI, Schiel DR (2003) Wave-related mortality in zygotes of habitat-forming algae from different exposures in southern New Zealand: the importance of 'stickability'. J Exp Mar Biol Ecol 290:229-245

Tilman D, Kareiva P (1997) Spatial ecology: the role of space in population dynamics and interspecific interactions. Princeton University Press, Princeton, NJ 
Tuya F, Boyra A, Sánchez-Jerez P, Haroun RJ, Barberá C (2004a) Relationships between rocky-reef fish assemblages, the sea urchin Diadema antillarum and macroalgae throughout the Canarian Archipelago. Mar Ecol Prog Ser 278:157-169

Tuya F, Boyra A, Sánchez-Jerez P, Haroun RJ, Barberá C (2004b) Can one single species determine the structure of a rocky benthic community: the case of the black longspined sea urchin Diadema antillarum in the eastern Atlantic. Hydrobiologia 519:211-21

Editorial responsibility: Otto Kinne (Editor-in-Chief), Oldendorf/Luhe, Germany
Underwood AJ (1997) Experiments in ecology: their logical design and interpretation using analysis of variance. Cambridge University Press, Cambridge

Underwood AJ, Chapman MG (1996) Scales of spatial patterns of distribution on intertidal invertebrates. Oecologia 107:212-224

Underwood AJ, Jernakoff P (1981) Interactions between algae and grazing gastropods in the structure of a low shore algal community. Oecologia 48:221-254

Submitted: April 27, 2005; Accepted: September 9, 2005 Proofs received from author(s): March 3, 2006 